Campos Neutrais - Revista Latino-Americana de Relações Internacionais Vol. 2, $\mathrm{N}^{\mathrm{O}}$ 3, Setembro-Dezembro de 2020. Santa Vitória do Palmar - RS.

\title{
Política Externa Migratória do Brasil: a política imigratória brasileira
}

\author{
Roberto Rodolfo Georg Uebel* \\ Sonia Ranincheski (in memoriam) ${ }^{* *}$
}

Resumo: Este artigo apresenta a Política Externa Migratória do Brasil (PEXMB). Surgida em um contexto de assertividade da Política Externa Brasileira (PEB), no período de 2003 a 2016, quando cerca de 2,1 milhões de imigrantes e solicitantes de refúgio chegaram no país, a PEXMB se configura como a política migratória do Brasil, dependente da PEB e das agendas do Ministério das Relações Exteriores. Analisaremos como este conceito surgiu a partir de eixos de inserção estratégica do Brasil, em duas regiões específicas: América Latina e África. Os resultados apontam que a sua sustentação se deu por pilares como as participações brasileiras em missões humanitárias, a concessão de bolsas de estudo e pesquisa para estrangeiros, a criação do visto humanitário, a emissão e isenção de vistos para grandes eventos desportivos, a discussão e a tramitação da nova Lei de Migração e a imigração subsidiada por meio do Programa Mais Médicos, tudo em um curto período, que chamaremos de hiperdinamização das migrações.

Palavras-chave: Política Externa Brasileira. Migrações Internacionais. Política Imigratória.

\section{Brazil's Foreign Policy for Migration: the Brazilian Immigration Policy}

Abstract: This article presents Brazil's Foreign Policy for Migration (PEXMB). Emerged in a context of the assertiveness of the Brazilian Foreign Policy (PEB), in the period from 2003 to 2016, where approximately 2.1 million immigrants and refugee seekers arrived in the country, the PEXMB is shaped as the immigration policy of Brazil, depending on the PEB and the agendas of the Ministry of Foreign Affairs. We will analyse how this concept arose from Brazil's strategic insertion axes in two specific regions: Latin America and Africa. The results show that it was supported by pillars such as Brazilian participation in humanitarian missions, the granting of scholarships and fellowships for foreigners, the creation of a humanitarian visa, the issuance and exemption of visas for major sporting events, the discussion and approval of the new Migration Law and the subsidized immigration through the Mais Médicos Programme, all in a short period, which we will call the hyper-dynamization of migrations.

Keywords: Brazilian Foreign Policy. International Migration. Immigration Policy.

\section{Introdução}

Este trabalho é resultado de uma compilação dos capítulos que apresentamos em tese doutoral (UEBEL, 2018) e que comporta um panorama atualizado dos perfis imigratórios do Brasil durante dois governos específicos: o de Lula da Silva (2003-2010) e o de Dilma Rousseff (2011-2016). Ademais, na referida tese, apresentamos três conceitos: política externa migratória, migrações de perspectiva e hiperdinamização das migrações. Também, trouxemos a ideia de imigração oeste-africana e discutimos a inserção estratégica do Brasil, na América Latina e na África, como fatores de atração de imigrantes no período supramencionado.

Desse modo, este trabalho abordará a hipótese central da tese, suas questões

\footnotetext{
* Doutor em Estudos Estratégicos Internacionais (UFRGS). Professor de Relações Internacionais da Escola Superior de Propaganda e Marketing (ESPM-POA).

** Doutora em Estudos Comparados sobre as Américas (UnB). Professora do Departamento de Economia e Relações Internacionais da Universidade Federal do Rio Grande do Sul. (in memoriam)
} 
norteadoras e a efetiva aplicação dos três conceitos criados. Previamente. chamados de "pilares da inserção estratégica do Brasil", passaram a ser classificados de "eixos", após o entendimento obtido, consensualmente, na qualificação de doutorado realizada em abril de 2017, e a partir das releituras e das revisões teóricas e conceituais que embasam o presente trabalho.

Mas o que são os eixos de inserção estratégica do Brasil? Consoante discutido em Uebel (2018), a política externa brasileira, salvo exceções pontuais em sua história, como durante o governo Michel Temer, sempre se pautou em programas e paradigmas específicos, tais como o integracionismo, o pan-americanismo, a terceira via, o pragmatismo independente, a interdependência, o latino-americanismo etc. Logo, os eixos de inserção estratégica são os direcionamentos e as pautas de uma determinada agenda política ou ambição externa do governo brasileiro.

Nessa direção, não poderia ser diferente para com a política externa migratória brasileira, que se apresenta como uma variante, uma consequência da política externa, ou ainda, como um amálgama da política imigratória, inexistente quanto à sua formalidade, com a própria política exterior do país. Porém, sua temporalidade e evolução nem sempre seguiram ao próprio sabor da política externa matriz, isto é, não raro, a práxis da política externa migratória seguiu rumos, tendências e, até mesmo, ideologias diferentes da sua política-mãe.

Outro fator que consideraremos, neste trabalho, é a questão dimensional, por assim dizer, a qual a política externa migratória brasileira e os subsequentes eixos de inserção estratégica do Brasil sofreram e verificaram continuidades e rupturas nas transições dos governos Lula da Silva para Dilma Rousseff, ou seja, ao contrário do inferido pelo senso comum e por parte da literatura acadêmica referencial, no que se refere às questões migratórias, não é possível afirmar em uma total continuidade de agendas e política entre os dois governos, pelo contrário, há mais rupturas que continuidades.

Para cada um dos dois governos estudados nesta pesquisa, nota-se a existência de três eixos de inserção estratégica que fomentaram os fluxos imigratórios em massa, isto é, a própria hiperdinamização imigratória sentida pelo Brasil no período estudado. A fim de facilitar a leitura e a compreensão da discussão proposta aqui, a Figura 1 sintetiza a relação entre política externa, política externa migratória e eixos de inserção estratégica, com a específica inclusão dos dois governos em tela. 
Figura 1 - Quadro-síntese da relação entre política externa, política externa migratória e eixos de inserção estratégica

\section{POLITICA EXTERNA BRASILEIRA}

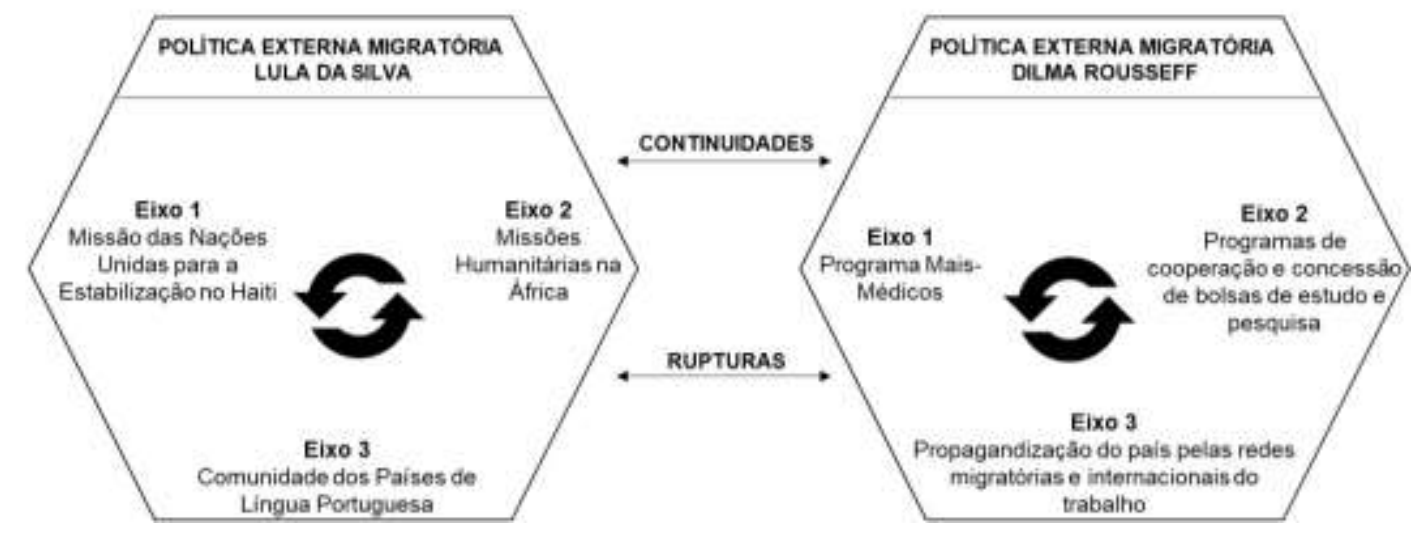

Fonte: Elaborada pelos autores.

Cabe analisar como essas duas peças quadrangulares - políticas externas migratórias - inserem-se no tabuleiro quadrado-retangular que é a política externa brasileira e como esses eixos, outrora chamados de pilares, sustentam a engrenagem que movimentou as continuidades e as rupturas entre os dois governos estudados; segundo Sassen (2007), são os próprios mecanismos de vinculação da política externa à política externa migratória.

Esse movimento, ainda dentro da abstração da Figura 1, ocasionou, portanto, a hiperdinamização das migrações no Brasil, migrações estas que chamamos de perspectiva, dado que não seguiam, com exclusividade, as motivações econômicas (imigrações econômicas) e as políticas-humanitárias (refúgio e solicitação de asilo), muito menos eram apenas motivadas por conflitos (migrações de crise), mas sim por um conjunto desses fatores, como vimos nos casos dos sírios, venezuelanos, cubanos, haitianos e coalinos/oeste-africanos, dentre outros grupos.

Desse modo, neste trabalho, optamos por dividir a discussão em quatro seções, duas destinadas aos dois governos estudados; a primeira, destinada à Introdução; e a quarta, para as Considerações Finais, isto é, compreender como se deu a transformação e a transmutação dos eixos de inserção estratégica por meio de agendas estratégicas (Visto humanitário, nova Lei de Migração, Visto da Copa/Olimpíadas) e do impeachment de 2016, que encerrou o ciclo de movimentação e hiperdinamização das migrações no Brasil, 
abrindo um novo panorama, que ficará para análises posteriores, uma vez que rompe, definitivamente, com todas as práxis, agendas e política externa migratória vigentes até então.

Como este estudo parte de um princípio multi e interdisciplinar, colhendo contribuições e discussões da Geografia, Economia, Direito e Ciência Política, julgamos relevante, também, traçar um panorama da política externa migratória de Lula da Silva com esses vieses, obviamente, respeitando os três eixos descobertos e escolhidos para discussão. Assim, o primeiro eixo a ser discutido, criticamente, será o "Brasil e a Missão das Nações Unidas para a Estabilização no Haiti”, que foi uma composição estratégica política, econômica, social e geopolítica da administração Lula da Silva para afirmação do Brasil como uma potência média e regional ao mesmo tempo, dentro de uma lógica tão neorrealista quanto a agenda de Celso Amorim, que se dizia, a despeito disso, pragmático.

Já o segundo eixo estudado dentro da PEXMB de Lula da Silva será a "Participação brasileira nas missões humanitárias na África", que, no âmbito acadêmico brasileiro, tem se restringido, cada vez mais, aos estudos estratégicos de segurança, à defesa e à cooperação técnica, com raríssimos estudos políticos e geopolíticos críticos sobre as intenções dessa participação brasileira na África, que, muitas vezes, também, passou desapercebida pelo mainstream acadêmico e midiático do país.

Cabe lembrar, por exemplo, que dentro desse quadro político do governo Lula da Silva, as missões humanitárias comandadas e ou gerenciadas pelo Brasil na África foram tão importantes quanto a concessão de bolsas de estudo e de pesquisa do governo Rousseff para o impacto motivacional das novas migrações. Obviamente, a PEXMB, além da MINUSTAH e da presença na África, também influenciou os fluxos de latino-americanos, entretanto, a América Latina consolidava-se mais como uma agenda política domésticaexterior do que como um eixo específico.

Por este motivo, os fluxos hiperdinamizados, durante a administração Lula da Silva, não foram tão intensos entre os latino-americanos, uma vez que ocorreriam como uma continuidade do projeto de integração latino-americana de Lula já na administração Rousseff, consolidados, inclusive, no Programa Mais Médicos.

O último eixo de inserção estratégica que trazemos para a discussão na política externa migratória de Lula da Silva é "A liderança atrativa brasileira na Comunidade dos Países de Língua Portuguesa", outro tema pouco considerado pelos nossos pares acadêmicos quando do estudo das motivações migratórias e das próprias imigrações nas últimas duas décadas, como se a irmandade linguística fosse apenas mera coincidência e 
não um fator preponderante na escolha pelo Brasil em detrimento de Portugal pelos lusoafricanos e timorenses (e, também, pelos próprios portugueses no rápido boom imigratório pós-crise de 2008).

Encerrada a discussão sobre os eixos de inserção estratégica e da PEXMB de Lula da Silva, imediatamente, transpomo-nos a 2011 com o debate crítico ante sua sucessora, que apresentou uma agenda confusa: tanto a política externa como a política externa migratória do seu governo foram díspares, dissonantes e, poucas vezes, se assemelhavam no discurso e na prática, porém, vivenciaram o boom da hiperdinamização imigratória do Brasil, que, ao cabo, provocou, além do impeachment, uma revisão e a promulgação da nova Lei de Migração.

Nesse contexto, começamos o estudo da PEXMB de Rousseff por meio de um dos seus programas-eixo mais polêmicos, o Programa Mais Médicos, que foi o primeiro programa de imigração subvencionada pelo governo/Estado brasileiro desde o Império, e teve um impacto significativo na socioeconomia brasileira, bem como na própria opinião pública, que, mais tarde, incentivaria o crescimento dos sentimentos xenofóbicos dentro da sociedade brasileira.

Entretanto, o Mais Médicos não foi o eixo primordial de sustentação e alavancagem da política externa migratória de Rousseff, tampouco o foram "Os programas de cooperação e concessão de bolsas de estudo e pesquisa", que são objeto de análise da segunda seção, porém ambos contribuíram para que as migrações de perspectiva também englobassem as categorias de profissionais qualificados e estudantes, mormente antes sempre condicionadas aos expatriados e à expatriação, uma tipificação que começa a tomar forma nos estudos migratórios brasileiros, muito influenciada pela literatura anglo-saxã (GREEN, 2009) e russa (MINBAEVA; MICHAILOVA, 2004) sobre o tema.

$\mathrm{O}$ eixo de inserção estratégica que, de fato, influenciou e fomentou o boom imigratório hiperdinamicamente vivido pelo Brasil foi, justamente, aquele que teve uma menor participação estatal-governamental, e sim uma maior presença das redes e atores não estatais, ou seja, aquilo que chamamos de "propagandização do país pelas redes migratórias e internacionais do trabalho como uma alternativa aos destinos tradicionais".

Conceitos emprestados da Geografia, as redes migratórias e internacionais do trabalho foram a principal força-motriz e o eixo de inserção estratégica que propiciaram a emergência de um cenário aberto, ainda que muito dinâmico e temporalmente diminuto, para a chegada em massa de imigrantes de perspectiva durante o governo Rousseff, algo que ficou muito evidente quando das entrevistas informais com imigrantes latino- 
americanos e africanos.

Apesar de não serem temas e conceitos novos - as redes migratórias já eram estudadas no século XIX -, a forma como se desenvolveram no Brasil e, mais especificamente, no governo Rousseff, foram muito peculiares quanto a sua dinamização, intensidade e espacialidade. Relembremos, novamente, como as imigrações ganharam um caráter essencialmente terrestre e físico naquele governo, mesmo para aquelas oriundas de além-mar, como as do oeste africano.

A questão escalar também reaparece nesta última seção dedicada à PEXMB de Rousseff, uma vez que as redes, obrigatoriamente, segundo a leitura de um mundo técnicocientífico-informacional (SANTOS, 1993), demandam a presença de múltiplas escalas para a sua execução e para a própria compreensão. Nesse contexto, portanto, não podemos refutar a ideia que muitos pares apresentam como migrações transnacionais e não internacionais aquelas que se desenvolveram e ainda se desenvolvem no Brasil contemporâneo, contudo este não é o foco do nosso debate aqui.

Para encerrar o trabalho e, também, a discussão, trazemos, na última seção, um arrazoado das continuidades e rupturas da política externa migratória brasileira entre os dois governos, bem como um apontamento das perspectivas de agenda e cenário imigratório do Brasil a partir da ruptura total advinda do impeachment de 2016, uma vez que a hiperdinamização migratória se encerrou e deu espaço para uma agenda transmutada com elementos da nova Lei de Migração, xenofobia contestatária e governamental e a emergência de um único fluxo, o de venezuelanos.

\section{Política Externa Migratória do Governo Lula da Silva}

Se a política externa geral de Lula da Silva se baseou em uma agenda programática e pautada no integracionismo latino-americano, africano, asiático e, sobretudo, terceiromundista ou entre as periferias do Sul Global, a sua política externa migratória percebeu algumas nuances sustentadas em três eixos de inserção e atuação estratégica: a participação brasileira na MINUSTAH, nas missões humanitárias na África e na Comunidade dos Países de Língua Portuguesa.

Esses três eixos, que serão analisados na presente seção, permitiram a criação de uma perspectiva, portanto uma motivação aos imigrantes de perspectiva, originários da América Latina, do Caribe e da África durante o período compreendido pela administração Lula da Silva. A sua política externa migratória encontrou certa consonância com a política externa geral e foi além disso, ela se sustentou, domesticamente, com um discurso de 
direitos humanos atrelado ao então anseio brasileiro de possuir um assento permanente no CSNU.

Retomando e sintetizando o que foi abordado em Uebel (2018), é importante salientar que a pauta imigratória do Brasil, no âmbito doméstico, no início dos anos 2000, era ainda incipiente e voltada à agenda de Fernando Henrique Cardoso, ou seja, o cerne do debate era o caso dos refugiados colombianos, palestinos e afegãos e a institucionalização da Lei do Refúgio de 1997.

Caso interessante de se observar é que Lula da Silva elegeu-se com uma inquestionável pauta e agenda dos movimentos sociais e dos direitos humanos, criando, ainda no seu primeiro governo, um ministério dedicado ao tema, porém, que pouco trabalhava a questão migratória, ainda centrada nas discussões do MJ e Itamaraty, além da ação prática da Polícia Federal, que viria a ser reforçada nos governos posteriores.

Ainda nas questões domésticas, a leitura crítica e acadêmica acerca da atuação governamental de Lula da Silva em relação aos imigrantes e refugiados parte de uma ótica de continuidade da agenda de Cardoso, contudo com novos paradigmas impostos pelo "neodesenvolvimentismo social" do Partido dos Trabalhadores, somados às agendas integracionistas latino-americanas e progressistas da época.

Nesse sentido, o tratamento dado aos imigrantes e refugiados pautou-se muito na questão social e nos direitos humanos, mas mais como um discurso a ser refletido externamente do que uma efetiva integração destes grupos na sociedade brasileira. E é neste bojo que se insere a atuação quase que exclusiva do MRE em relação à temática política-imigratória que viria a consolidar, segundo a nossa hipótese e inferência, a política externa migratória do Brasil.

É nessa maior inserção ou percepção do Itamaraty junto à questão migratória que percebemos e identificamos a ruptura de Lula da Silva com a agenda de Cardoso: no governo anterior, o MRE muito pouco se dedicava aos temas migratórios e, quando o fazia, era em relação aos brasileiros no exterior, e não aos imigrantes e refugiados no Brasil, embora já se contasse com uma comunidade estrangeira de número relevante - e crescente - no território brasileiro.

Se fôssemos traçar uma linha do tempo para identificar essa ruptura (ou surgimento) da política externa migratória brasileira, poderíamos inserir alguns anoschave, como 2004, quando do surgimento da MINUSTAH, 2006, com a primeira Cúpula América do Sul-África, e 2008, com o estabelecimento da União de Nações SulAmericanas. Observemos como a PEXMB era tão condicionada à política externa "ativa e 
altiva" de Lula da Silva, Amorim e Garcia.

Neste condicionante, é possível identificar e reforçar como as migrações de perspectiva se verificam mais como uma consequência da política externa brasileira do que como uma causa, ao contrário de Estados como Canadá e Austrália, onde as políticas são esboçadas para os potenciais imigrantes.

Consideramos oportuno reforçar esse argumento, uma vez que, quando discutirmos a política externa migratória de Rousseff nas próximas seções, veremos que as consequências imigratórias serão muito maiores que as causalidades, isto é, projetou-se uma PEXMB para um determinado perfil de imigração e colheu-se um resultado muito além, o que explicará, inclusive, os elementos de xenofobia governamental e institucional desde o final da administração Rousseff até o governo de Michel Temer, perpassando a própria agenda eleitoral de 2018.

Com a institucionalização - ou nascimento - da política externa migratória durante o governo Lula da Silva, outros fóruns temáticos sobre o tema foram alçados a voos maiores pela coordenação e centralização do tema no Itamaraty, ou seja, à mesma época, a questão imigratória também ganharia espaço e abordagem nos grupos de trabalho do Mercosul, UNASUL, OEA e nos demais fóruns regionais, inter-regionais e intercontinentais, como os BRICS, ASPA, IBAS, BASIC, FEALAC etc.

Como a literatura crítica de política externa brasileira dos dias de hoje salienta, a PEXMB de Lula da Silva também foi baseada em uma diplomacia presidencial e em uma política externa das cúpulas, algo que se transformaria nos dois governos subsequentes, abrindo margem para que a política doméstica também passasse a se preocupar e a se inserir nas questões migratórias.

Do ponto de vista crítico, apesar de ser indiscutivelmente positivo o fato de que as migrações ganhassem olhar e atenção governamental de forma mais acentuada no governo Lula da Silva, não podemos deixar de mencionar que, para um governo que se colocava como representante dos movimentos sociais e dos direitos humanos, não inserir imigrantes e refugiados em sua política doméstica demonstrou um grande lapso político e uma oportunidade de consolidação de uma nova lei de migração no momento em que teria a maior aprovação popular e congressista, muito diferente de 2017, quando, finalmente, foi aprovada e sumariamente vetada pelo então presidente Michel Temer.

Essa questão crítica reflete-se no próprio caso dos afegãos, que chegaram, ainda, em 2001, após os ataques e a invasão norte-americana no Afeganistão e receberam do então candidato Lula da Silva, em 2002, a promessa de que seriam plenamente integrados à 
Campos Neutrais - Revista Latino-Americana de Relações Internacionais Vol. 2, $\mathrm{N}^{\mathrm{O}}$ 3, Setembro-Dezembro de 2020. Santa Vitória do Palmar - RS.

sociedade brasileira, algo que não ocorreu e demonstrou a fragilidade da inexistente política imigratória brasileira, como registra a reportagem do jornal O Estado de São Paulo de maio de 2003:

\begin{abstract}
A terça-feira úmida e abafada de Porto Alegre foi o último dia de exílio para três famílias afegãs que passaram vários anos fugindo de guerras e perseguições e vieram para o Brasil em abril do ano passado. Os três casais e oito filhos embarcaram no fim da tarde com destino a São Paulo, de onde seguiriam para Frankfurt e, depois, para Cabul. Para duas das famílias, haverá outra etapa, o deslocamento de Cabul para cidades do interior do Afeganistão, onde deverão chegar no sábado. Ao se despedirem dos voluntários da Central de Orientação e Encaminhamento (Cenoe), os afegãos não escondiam a emoção. O professor Nesar Ahmad Fagiri, de 57 anos, pediu que o filho Ali, de 13 anos, traduzisse para o português o agradecimento pelo acolhimento que a organização não governamental, conveniada com o Alto Comissariado das Nações Unidas para Refugiados (Acnur), deu ao grupo em Porto Alegre. O rápido discurso mostrava a maior dificuldade que os afegãos adultos tiveram no Brasil, o aprendizado da língua e a adaptação aos hábitos ocidentais. Os jovens, ao contrário, partiram dominando o português, vestindo roupas idênticas à de qualquer brasileiro da mesma idade, e hesitantes. "Quero ir, mas também gostaria de ficar", disse Assieh Fagiri, 18 anos, irmã de Ali. "As pessoas são muito boas no Brasil", justificou. A saudade de familiares e a perspectiva de recuperar o antigo padrão de vida na reconstrução do Afeganistão motivou os refugiados a renunciarem à proteção da ONU para voltar à terra natal. "Eles perceberam que levariam vários anos para conquistar bons salários no Brasil", observa a assistente social Sônia Mesquita, que conviveu com o grupo durante um ano (FAMÍLIAS de refugiados afegãos deixam o Brasil, 2003).
\end{abstract}

Esse episódio da não integração de migrantes de perspectiva (tanto imigrantes como refugiados e outras categorias legais de estrangeiros) expõe um dos pontos mais sensíveis da política externa migratória brasileira: a dificuldade de integrá-los na sociedade, no mercado de trabalho e na cidadania brasileira, o que não deixa de ser contraditório, em se tratando de um dos países mais multiculturais do mundo.

Com essa questão, é possível afirmar que sim, apesar de todo o caráter social e humanitário previsto no programa partidário de Lula da Silva, o fato de não prever a integração e o acolhimento daqueles que são nacionais não brasileiros, demonstra um tipo, ainda que tímido, se comparado às outras agendas partidárias do Brasil, de xenofobia governamental, política e institucional.

Isso não significa que a administração Lula da Silva tenha sido xenofóbica, pelo contrário, há elementos que apontam para uma tendência, que se verificaria com mais destreza, posteriormente, no governo Rousseff, de convergência e de incorporação da agenda globalista de direitos humanos migratórios no país, porém, a não apresentar 
Campos Neutrais - Revista Latino-Americana de Relações Internacionais Vol. 2, $\mathrm{N}^{\mathrm{O}}$ 3, Setembro-Dezembro de 2020. Santa Vitória do Palmar - RS.

condições, como o caso supramencionado dos afegãos, para que imigrantes e refugiados se integrassem no Brasil, demonstra elementos de xenofobia institucional.

Porém, se de um lado há essa evidência, também há que se mencionar que foi, durante a vigência da PEXMB de Lula da Silva, que se registrou o maior declínio possível da xenofobia governamental, se comparado aos seus dois sucessores. Entretanto, apenas no seu segundo mandato é que poderemos vislumbrar tais circunstâncias.

Vizentini (2005) e Fonseca (2011) postulam que o primeiro governo de Lula da Silva foi mais de continuidade aprimorativa da política externa de Cardoso e semeadura das bases da sua política externa ativa e altiva, que vigoraria, de forma mais expressiva, inclusive no que se refere à PEXMB, durante o seu segundo mandato, entre 2007 e 2010.

E é neste segundo mandato em que veremos a efetivação da inserção estratégica do Brasil na América Latina, Caribe e África, com as subsequentes repercussões de caráter imigratório, como o primeiro boom, já no final do governo Lula da Silva, de haitianos e a chegada massiva de luso-africanos e sul-americanos no Brasil, em busca de melhores condições laborais e sociais, vislumbrados por uma perspectiva de viver em um prospectivo global power como o Brasil, já que assim o era propagandeado, tanto pela esfera governamental como pelos novos imigrantes.

Ainda em relação à política externa migratória de Lula da Silva, seguindo aquela nossa linha temporal imaginária, podemos afirmar que, no seu segundo mandato, com uma já fixada política externa voltada ao Sul Global, os temas migratórios voltaram com mais força e menos resistência do Itamaraty à colaboração dos demais órgãos estatais, onde, finalmente, o ministério dos Direitos Humanos - então uma secretaria com status ministerial - ganharia mais espaço, e os interlocutores do MJ e do Ministério do Trabalho e Emprego, por meio do CONARE e CNIg, respectivamente, teriam mais voz dentro do próprio Itamaraty.

Dois fatos evidenciam essa mudança de postura, o primeiro, em 2008, quando o então chanceler Celso Amorim ativou os mecanismos de vinculação do Mercosul para uma posição firme em relação às novas restrições migratórias da União Europeia, conforme segue na reportagem a seguir:

Por sugestão do governo brasileiro, os presidentes dos países do Mercosul vão divulgar nesta terça-feira uma declaração conjunta "rejeitando" as novas regras de repatriação de imigrantes da União Europeia (UE). Inicialmente, a declaração se limitaria a falar em "preocupação" do Mercosul com as novas diretrizes, aprovadas no último dia 18 pelo Parlamento Europeu, que criminalizam a imigração ilegal. No 
entanto, segundo negociadores brasileiros e argentinos, por sugestão do ministro das Relações Exteriores, Celso Amorim, os presidentes farão uma declaração mais enfática, "rejeitando" as novas regras da União Europeia. As novas diretrizes estabelecem detenção por um período máximo de 18 meses, antes da expulsão do imigrante, além da proibição do seu retorno ao território europeu por um período de cinco anos. [...] A declaração conjunta, definida nesta segunda-feira, pretende ainda mostrar "unidade" do Mercosul (Brasil, Argentina, Paraguai, Uruguai) e dos sócios e convidados do bloco - Chile, Bolívia e Equador. A Venezuela, que também participa da reunião de líderes do Mercosul e países convidados, realizada em San Miguel de Tucumán, na Argentina, depende apenas das aprovações dos congressos do Brasil e do Paraguai para se tornar membro pleno do bloco. A preocupação em demonstrar "unidade" no Mercosul ocorre em um momento em que a região mostrase dividida em relação às discussões sobre a Rodada de Doha de liberalização do comércio mundial. De um lado, estão Brasil, Uruguai, Paraguai, Chile e Peru. De outro, Argentina, Venezuela e Bolívia, que defendem maior proteção às suas indústrias e maiores compensações a seus produtos para abertura de seus mercados à produção dos países desenvolvidos. [...] Além desta declaração de "rejeição" à nova política de imigração da UE, os presidentes vão assinar uma medida que determina o fim da exigência do uso de passaporte para os que vivem na América do Sul e viajam pela região. Esta medida também foi uma iniciativa brasileira, apesar de a presidência do bloco ter ficado durante os últimos seis meses com a Argentina. Por enquanto, por questões burocráticas de cada país, a medida não incluirá Venezuela, Guiana e Guiana Francesa. Nas reuniões realizadas nesta segunda-feira, autoridades da área econômica avançaram ainda nos últimos detalhes para a eliminação do dólar das transações comerciais entre Brasil e Argentina. A medida entra em vigor em setembro. Os presidentes devem anunciar ainda a criação de um fundo que servirá de garantia para que pequenas e médias empresas tenham respaldo financeiro quando quiserem empréstimos nos bancos públicos e privados dos países da região. A reunião termina nesta terça-feira. Segundo a imprensa argentina, o presidente da Bolívia, Evo Morales, confirmou que jogará uma partida de futebol em Tucumán. É esperado ainda que Morales e o colega venezuelano Hugo Chávez realizem um comício juntos na noite de terça-feira, quando outros líderes da região, como o presidente Luiz Inácio Lula da Silva, já deverão ter embarcado de volta a seus países, de acordo com a programação oficial (MERCOSUL rejeita novas regras de imigração da UE, 2008).

Fica evidente, a partir da leitura da reportagem anterior, que o governo brasileiro começava a enxergar a pauta migratória como um ponto a seu favor no caminho à sua consolidação como regional power e ao então sonhado assento definitivo no CSNU.

Segundo os documentos do Mercosul, aquela foi a primeira declaração conjunta de seus líderes em prol de uma questão migratória.

Apesar disso, um elemento que não pode passar despercebido, na presente pesquisa, é a menção que Amorim e, portanto, Lula fazem em relação à unidade do Mercosul, conforme o estrato da reportagem acima: "A preocupação em demonstrar "unidade" no 
Campos Neutrais - Revista Latino-Americana de Relações Internacionais Vol. 2, $\mathrm{N}^{\mathrm{O}}$ 3, Setembro-Dezembro de 2020. Santa Vitória do Palmar - RS.

Mercosul ocorre em um momento em que a região mostra-se dividida em relação às discussões sobre a Rodada de Doha de liberalização do comércio mundial” (Idem, 2008).

Ou seja, mais uma vez, a PEXMB está atrelada a uma política externa geral (no caso citado, em relação às questões comerciais), o que, a partir da leitura de autores como Seyferth (2008) e Reis (2011), corrobora o caso único do Brasil em todo o sistema internacional, de uma política migratória - ainda que não existente e/ou independente dependente e subserviente à uma política externa, sendo ambas inseparáveis, independentemente de qualquer espectro político na Presidência da República, o que ficará ainda mais evidente no governo Rousseff.

Para finalizar a seção e justificar a nossa crítica à PEXMB de Lula da Silva, que, apesar dos seus avanços, não permitiu integração e acolhimento social dos imigrantes de perspectiva, sobretudo os haitianos e africanos, trazemos a breve entrevista do chanceler Amorim, em 2012, como Ministro da Defesa, quando revê, também, criticamente, a postura do governo brasileiro face às questões migratórias:

\begin{abstract}
O Brasil terá que repensar sua política de imigração devido aos impactos econômicos gerados pela entrada cada vez maior de estrangeiros irregulares no país, em busca de melhores condições de vida. A opinião é do ministro da Defesa, Celso Amorim, que por quase uma década foi ministro da Relações Exteriores, nos governos de Itamar Franco (19931995) e de Luiz Inácio Lula da Silva (2003-2010). [...] - Não dá para se tornar a sexta economia do mundo impunemente. Normalmente, as pessoas saíam do Brasil. O Brasil ficou melhor agora. As pessoas querem entrar no Brasil. Naturalmente teremos que estudar como agir diante dessa nova situação. Não são apenas haitianos, mas brasileiros que estão voltando. Temos que procurar exercitar o mesmo espírito humanitário que está presente (com as Forças de Paz) no Haiti, de uma maneira compatível com os nossos meios. [...] - Precisamos atuar de maneira equilibrada para que as pessoas não venham a encontrar aqui situações até mais graves, seja porque são exploradas por coiotes ou porque encontram condições em que não podem ser adequadamente tratados (POLÍTICA de imigração brasileira precisa ser revista..., 2012).
\end{abstract}

Essa citação reflete, exatamente, a nossa crítica em relação à PEXMB e, também, demonstra a desconexão entre os operadores (atores) estatais e as próprias instituições: para Amorim, o Brasil possuía uma política de imigração, enquanto, para o MRE, se tratava de uma agenda de política externa como qualquer outra.

Ao mencionar a atuação estratégica do Brasil no Haiti, por meio da MINUSTAH, quando invoca um "espírito humanitário", Amorim define, exatamente, a política externa migratória de Lula da Silva: humanitária externamente, incompatível domesticamente. 
Assim, nessa esteira, discutiremos, na próxima seção, como a externalidade da inserção estratégica do Brasil, nos três episódios já mencionados, não encontrou ressonância no âmbito doméstico no que se refere ao acolhimento e à integração dos imigrantes de perspectiva e, também, a não internalização da agenda migratória e como isso influenciou a PEXMB de Dilma Rousseff.

Para sintetizar: o tratamento humanitário que haitianos e africanos (mas também latino-americanos e caribenhos em geral) prospectaram, no exterior, com a propaganda dos operadores brasileiros (Forças Armadas, representações diplomáticas, entes estatais, governamentais e não governamentais brasileiros em geral), não foi verificado, em nenhum momento ou nível, quando da sua chegada e instalação no território brasileiro. Por isso: hiperdinamização das migrações de perspectiva moveram-se, tão logo, ao não encontrarem o acolhimento humanitário no Brasil.

\section{Política Externa Migratória do Governo Rousseff}

Em Uebel (2018), arguimos que a política migratória, no Brasil, é condicionada, dependente e indissociável da política externa. A política externa brasileira e a inserção estratégica do Brasil na África e América Latina foram motivadoras das migrações de nacionais daquelas regiões nas últimas duas décadas.

Agora, na parte final do presente trabalho, serão analisados os elementos que compõem a política externa migratória do governo Rousseff. Esta seção, também, abordará como se processou a incorporação da agenda globalista de direitos humanos migratórios na PEXMB de Rousseff, inclusive com o episódio da tentativa de criação de uma Estratégia Nacional de Migração por meio da $1^{\mathrm{a}}$ Conferência Nacional sobre Migrações e Refúgio $\left(1^{\mathrm{a}}\right.$ COMIGRAR), realizada em maio/junho de 2014.

A administração Rousseff se caracterizou como aquele governo que mais perto chegou da criação e da efetivação de uma Política Migratória Nacional, semelhante àquelas existentes em países como Canadá, Austrália e Argentina, por exemplo, ou seja, dissociada, completamente, da política externa e do próprio MRE, que configuraria como uma força de propulsão da referida política, mas não seria o seu principal agente-coordenador.

Contudo, é justamente o próprio MRE que encabeçará e dominará a agenda propositiva de migrações durante toda a administração Rousseff, desde a organização da $1^{\mathrm{a}}$ COMIGRAR até a consultoria à Casa Civil; já, no governo Michel Temer, para a elaboração dos vetos à nova Lei de Migração, a discussão começou ainda durante o governo Rousseff. 
Entretanto, há que se salientar que, se, por um lado, o Itamaraty galgou o posto de coordenador e executor da política externa migratória brasileira, por outro lado, sofreu revezes de descrédito e certo desprezo pela presidente Rousseff, que teve, ao longo de seus quase seis anos de governo, três chanceleres, quebrando, portanto, a tradição de manutenção e de estabilidade do posto máximo da diplomacia brasileira.

Os três chanceleres Antonio Patriota (01 de janeiro de 2011 a 26 de agosto de 2013), Luiz Alberto Figueiredo (28 de agosto de 2013 a 01 de janeiro de 2015) e Mauro Vieira (01 de janeiro de 2015 a 12 de maio de 2016) tiveram uma participação tímida na administração Rousseff se comparados à atuação ativa e proativa de Celso Amorim - que fora promovido a Ministro da Defesa de Dilma Rousseff -, e tentaram manter o papel do Brasil como potência regional e global player, embora não tenham conseguido evitar que o país fosse alvo dos mais variados tipos de ataque, como o caso da espionagem norteamericana (UOL, 2013) e do descrédito por parte de Israel, que chegou a chamar o país de “anão diplomático" (G1, 2014).

Nesse contexto, se desenrolaram, no Brasil, processos migratórios hiperdinamizados de latino-americanos e africanos, com destaque para os subgrupos de caribenhos e oeste-africanos, que, ao cabo, demandaram um reposicionamento da então vigente PEXMB ainda do governo Lula da Silva, o que demonstra que não ocorrera uma ruptura de imediato das políticas daquele governo para a sua sucessora - e correligionária com a mudança de governo.

Pelo contrário, veremos que as rupturas de um governo para outro se processarão apenas com dois episódios, que remontam o período de 2012 a 2014: a criação do visto humanitário para sírios, haitianos e oeste-africanos e o programa de imigração subsidiada do Programa Mais Médicos; ademais, tal ruptura é provocada pela crise imigratória venezuelana, que emerge, ainda, no final do governo Rousseff.

Durante a subgestão de Antonio Patriota como chanceler, e a chamamos assim, pois, ao contrário da administração Lula da Silva, a diplomacia e a política externa verificadas em Dilma Rousseff combinavam um padrão de diplomacia presidencial autocentrada, isto é, com pouca interferência direta do Itamaraty, a não ser aquela pautada no comércio exterior, em negócios internacionais e em cerimonial/protocolar. A questão migratória foi tratada de forma muito semelhante àquela de Celso Amorim embora, no seu discurso de posse como chanceler, o tema tenha surgido de forma objetiva: 
Nossos próprios imperativos de desenvolvimento econômico, social e tecnológico orientarão a busca de parcerias em uma variedade de temas, que incluirão a educação, a inovação, a energia, a agricultura, a produtividade industrial, a defesa; sem descuidarmos do meio ambiente, da promoção dos direitos humanos, da cultura, das questões migratórias (DISCURSO do Ministro Antonio de Aguiar Patriota por ocasião da cerimônia de transmissão do cargo de Ministro de Estado das Relações Exteriores, 2011, grifo nosso).

Salientamos, também, que, durante os seus dois primeiros anos de governo, Rousseff encontrou um cenário de relativa prosperidade econômica e política no Brasil, redução do tensionamento social e equilíbrio dos influxos imigratórios, já elevados em virtude da imigração haitiana, mas ainda aquém do boom de 2013 e 2014 . Nesse contexto, seria evidente uma despreocupação institucional em relação à questão imigratória, ainda sob o guarda-chuva do Itamaraty e da política externa brasileira.

Todavia, é justamente por uma questão migratória que o chanceler Patriota fora demitido por Rousseff:

O motivo da demissão foi o episódio do senador boliviano Roger Pinto Molina, que estava asilado havia um ano na embaixada brasileira em La Paz e foi trazido para o Brasil em um carro oficial brasileiro, embora não tivesse autorização do governo boliviano para deixar o país (DILMA demite ministro Patriota..., 2013).

A questão da concessão de asilo político, embora não seja objeto do presente trabalho, se constituiu em importante tema na macrodiscussão acerca das migrações e da própria Lei de Migração em tramitação no Congresso Nacional, e que, conforme supramencionado, levou à demissão de Patriota.

Consoante observado, tanto a diplomacia brasileira como a PEXMB estiveram à margem e à sombra do governo Rousseff durante a chancelaria de Antonio Patriota, e ganhariam destaque, apenas, com Figueiredo e Vieira; o primeiro, como chanceler provisório até janeiro de 2015; e o outro, como partícipe da "reforma ministerial" de Rousseff para o seu segundo governo, que, inclusive, trocou seu slogan de "País rico é país sem pobreza" para o "Pátria Educadora".

É na gestão de Luiz Alberto Figueiredo, então embaixador do Brasil na ONU, que o tema migratório passará a ser tratado como assunto de primeira ordem, tanto pelo Itamaraty como pelo próprio governo, em virtude de dois episódios: o boom imigratório de haitianos e oeste-africanos e a imigração subsidiada por meio do Programa Mais Médicos, notadamente a de cubanos. 
Nesse período, começaram a ser realizadas, por meio da promoção do MRE, as conferências locais e estaduais de migrações e refúgio, que se reuniriam e seriam consolidadas na $1^{a}$ COMIGRAR, cujo principal órgão patrocinador foi o Itamaraty. A conferência realizada em São Paulo, no final de maio e no início de junho de 2014, foi uma resposta do governo federal às demandas populares, institucionais e dos próprios imigrantes em relação a uma postura necessária face ao cenário crítico pelo qual passavam imigrantes e refugiados.

Cabe lembrar que, desde junho de 2013, Rousseff enfrentava grande pressão popular, por meio de manifestações e atos políticos apartidários, que culminaram com as "Jornadas de Junho" e com a fecundação dos movimentos nacionalistas pró-impeachment de 2014 e 2015. Resumindo: a política externa migratória de Rousseff nasceu junto com a efervescência política do Brasil e no seio das manifestações populares e políticas oposicionistas que levaram à queda da presidente em 2016.

De acordo com Uebel (2017), a crise imigratória vivida pelo Brasil começara a partir de um ciclo de crises iniciado, em 2013, com as "Jornadas de Junho", conforme segue: crise institucional $\rightarrow$ crise política $\rightarrow$ crise econômica $\rightarrow$ crise social $\rightarrow$ crise imigratória. Ou seja, os próprios episódios de xenofobia que, hoje, se processam contra refugiados venezuelanos têm o seu embrião na onda de protestos da sociedade conservadora e nacionalista brasileira em 2013 e inação do governo federal para a inibição de tais discursos. Isso ficará evidente a partir da leitura de Souza (2017).

Em relação ao pensamento e às ações do Itamaraty durante a gestão de Figueiredo como chanceler, podemos identificar, em seu discurso à Comissão de Relações Exteriores e Defesa Nacional da Câmara dos Deputados, em audiência pública realizada em 07 de maio de 2014, portanto, no ínterim da hiperdinamização imigratória de 2014 e de execução do Programa Mais Médicos, elementos que corroboram as nossas hipóteses que discutimos até o presente, conforme seguem nos nossos grifos na citação a seguir:

Eu peço vênia para os Srs. Deputados para buscar condensar as respostas em temas. Aí eu pedirei desculpas se alguma coisa se perder no meio desse caminho. E, sem nenhuma ordem específica, vamos começar com o caso dos haitianos, porque eu acho que foi o mais mencionado. No caso Haiti, é importante deixar claro que o Brasil é o único país do nosso continente, e um dos poucos países do mundo, que adota uma política migratória especial de caráter humanitário para o caso dos haitianos. Os haitianos vêm para cá, como bem foi ressaltado pela Deputada Perpétua, porque sonham com a prosperidade brasileira. O Brasil é um país que efetivamente atrai, e os haitianos têm, talvez, as mais altas taxas de desemprego no mundo. O número de nacionais haitianos que 
querem sair do Haiti é muito grande, e nós os adotamos, dentro das nossas melhores tradições uma política de acolher. O Brasil é formado, além do componente indígena, por etnias que viera para cá. Portanto, somos um país de acolhimento natural de imigrantes. E nós não renegamos, de jeito nenhum, essa política. Porém, como foi apontado, há problemas, especialmente a ação dos coiotes que trazem alguns haitianos, muitos, enfim, em situação precária, mediante riscos, e temos que ter ações claras para diminuir, coibir, organizar isso. Então, esta é a pergunta: o que está sendo feito? Em primeiro lugar, nós temos que estimular os haitianos a entrarem de maneira legal no Brasil; temos que deixar claro para eles que, ao entrarem de maneira legal, eles terão um apoio, um respaldo muito mais amplo do que caso entrem de forma ilegal; porque, caso venham legalmente, com visto, eles usarão os portos de entrada natural do País - São Paulo, Rio de Janeiro, Belo Horizonte, Fortaleza, Salvador, enfim, e vários outros locais onde há aeroportos que servem o tráfego internacional - portanto, onde eles não estão sujeitos a qualquer tipo de constrangimento. Para isso, portanto, temos que buscar aprimorar a concessão de vistos. Já fizemos isso. Só para dar uma ideia, de 2012 até hoje, a nossa Embaixada no Haiti decuplicou a concessão de vistos. Isto quer dizer, com o enorme esforço vocês podem imaginar que não é algo simples -, decuplicou a concessão de vistos. Com esse enorme esforço, nós concedemos, no último ano, para haitianos, algo muito próximo a 10 mil vistos. Por quê? Porque nós queremos estimular aqueles que querem vir ao Brasil que venham, mas que venham amparados por uma documentação, por um visto; que entrem e busquem o seu lugar no Brasil, como tantos buscaram em outras épocas. É isso o que nós queremos. Por que a utilização do coiote? Aí existem várias razões. Algumas delas têm a ver com dificuldades que alguns cidadãos no Haiti têm em se documentarem. Quer dizer, quem quer ir para outro país tem que tirar um passaporte; muitas vezes, tirar um passaporte leva um certo tempo e, como foi dito pela Deputada Perpétua, eles têm uma certa pressa. Aqueles que têm passaporte e que nos buscam, terão o visto concedido de uma forma simplificada. Porém, tem que ser algo consciencioso. Nós temos que avaliar se o cidadão que está querendo vir tem bons antecedentes. Enfim, não se pode simplesmente atuar de forma irresponsável. Então, leva certo tempo: 3, no máximo 4 semanas. Esta é a via que o Governo brasileiro quer e eu estou seguro de que esta é a via que todo brasileiro quer: que as pessoas que entrarem aqui não entrem de maneira ilegal, entrem de forma documentada. Nossa legislação, tendo em conta nossa capacidade de acolhimento, nossas melhores tradições nessa área, permite a toda pessoa que, ao chegar ao País, ainda que indocumentada - o caso dos haitianos que entram pelo Acre -, busque refúgio no Brasil. Portanto, não precisaria de visto. Ele chega e diz: Peço refúgio. Ao pedir refúgio, é obrigação da autoridade policial, no caso a Polícia Federal, conceder documento que dê a essa pessoa status provisório, que é o daquele que pediu refúgio, mas o refúgio ainda não foi concedido. (Intervenção fora do microfone. Ininteligivel.) [...] Não, refúgio por questões humanitárias, por questões de dificuldades econômicas. Então, a nossa legislação é absolutamente generosa nessa área e permite que isso seja feito. É claro que isso tem causado no Acre uma série de dificuldades que têm a ver com aqueles que, apesar dos riscos do trajeto, apesar do dinheiro que estão pagando para o coiote - que, no nosso caso, é uma despesa que não vão ter -, enfim, buscam essa entrada que talvez seja vendida. Vendida não é o termo, mas que talvez o boca a boca diga: 
Ah. Mas é mais fácil ir pelo Acre. É mais rápido. Não é mais fácil. Não é mais fácil (BRASIL, 2014, grifos nossos).

Essa fala de Figueiredo representa, de forma didática, como era a percepção da PEXMB de Rousseff e como o governo percebia as questões migratórias. A começar pela construção do discurso de "prosperidade brasileira", que se assemelha muito com o "Brazilian dream" ou com o "Eldorado brasileiro". Na referida citação, fica evidente, também, que as imigrações de haitianos e oeste-africanos se davam de acordo com a perspectiva de um cenário positivo e acolhedor por parte do Brasil e de suas instituições, o que não, necessariamente, se verificou, na prática, posteriormente.

Ademais, frisamos dois elementos importantes ainda presentes na administração Rousseff e sua PEXMB: o caráter securitário das migrações e o reconhecimento da legislação que preveria uma concessão de refúgio por questões econômicas, que nós chamamos de "imigrações de perspectiva".

Dentre esses elementos, a política externa migratória de Rousseff também inovou ao reconhecer a importância econômica da imigração - muito além dos anseios humanitários do Brasil em recebê-los. E a citação, a seguir, aponta para a confirmação de uma das argumentações mais importantes na presente pesquisa: a propaganda governamental do Brasil como país de destino para imigrantes a partir da sua inserção estratégica:

Além de multiplicarmos a concessão de vistos, fizemos uma campanha no Haiti de esclarecimentos, com distribuição de folhetos em créole e francês: Olha, a via correta é o visto. Peçam o visto. Mas, aí, voltamos ao caso daqueles que são indocumentados. Enfim, há vários fatores de premência que atuam. Então, o Governo está empenhado em duas coisas. Primeira, garantir que o visto seja a via, e nós vamos começar nova campanha no Haiti. Inclusive, quando eu estive lá, já faz uns meses, no meu diálogo com o Presidente Michel Martelly, combinei com ele até o uso do rádio. O rádio é um fator de comunicação muito importante no Haiti. Então, dar mensagens pelas rádios de que há uma via correta que traz benefício a quem a segue. Segunda, deixar muito claro - e isso vai ser parte desta nova campanha - que quem vier com visto vai ter prioridade nos programas de acolhimento, ou seja, nos programas de documentação, de inserção no mercado de trabalho, de assistência, de treinamento profissional enfim, para que fique muito claro que existe uma porta da frente aberta para eles e que essa porta aberta leva a que o acolhimento seja de qualidade melhor. Outra coisa é a criação de diálogo com os Governos Estaduais e Municipais. Já houve início de diálogo com o Governo de São Paulo, ou está havendo. Mas essa era uma decisão de início de diálogo com o Governo do Estado de São Paulo e do Município de São Paulo para buscar maneiras de 
organizar o acolhimento daqueles que chegarem por Guarulhos, daqueles que chegarem de forma legal. É claro, humanitariamente, nós entendemos que o apoio tem que ser dado a todos, mas vamos privilegiar sim aqueles que chegarem de forma legal, para mostrar claramente que nossas portas estão abertas. A imigração é uma característica do brasileiro, e, portanto, neste caso, também vai ser e tem sido. Vamos, então, atuar não só aqui, organizando novos pontos de acolhimento ao longo do País, para que não seja a carga inteira no Acre, até porque, se a situação de acolhimento no Acre for melhor do que nas cidades que são pontos de entrada, ninguém vai querer vir de avião para São Paulo, porque, chegando lá, não vai ter acolhimento, não vai ter documento, não vai ter nada. E, se for pelo Acre, vai ter? Não pode ser assim. A SRA. DEPUTADA PERPÉTUA ALMEIDA - Só um aparte. As entradas ilegais por Mato Grosso e Amazonas acabaram, porque lá eles não tinham apoio nenhum, e o Estado do Acre os acolhia, com dificuldades, mas os acolhia. Então, virou a rota preferencial. O SR. MINISTRO LUIZ ALBERTO FIGUEIREDO MACHADO - Exatamente. Portanto, essa é uma questão importante. O Governo está debruçado sobre ela, buscando sempre contato com os Governos Estaduais e Municipais para estabelecer medidas desse tipo. Além das medidas aqui, nós temos medidas tomadas no Haiti e temos também outras medidas. Nós temos cooperações com o Haiti que levam à fixação dos haitianos no país, como centros de capacitação profissional em término de construção. Eu inaugurei um muito semelhante ao do SENAI na Jamaica. São centros importantes que capacitam mão de obra, e esse vai ser mais um deles. Então, além de ações no Haiti e aqui, também estamos buscando, junto com o Ministério da Justiça, contatos nos países que são rota de entrada para o Acre, especialmente, no caso, Equador e Peru, para que, com cooperação internacional nossa com eles, haja fortalecimento. Nós já estamos dando muitos vistos a haitianos no Equador e no Peru, porque eles chegam lá e já há orientação para que busquem o visto, e fazem isso. Então, já há vários casos de vistos que são dados também nas nossas Embaixadas de trânsito. Queremos fortalecer a cooperação tanto com Peru quanto com Equador, que têm sido receptivos, devo dizer, para que haja esse ordenamento do fluxo e para que a entrada seja de qualidade, sem riscos, sem expor o imigrante à violência, ao risco, à ação de coiotes, e que o acolhimento também seja de qualidade (BRASIL, 2014, grifos nossos).

Ora, fica evidente o interesse brasileiro na promoção do fluxo imigratório haitiano, que viria a se confirmar, também, no caso dos oeste-africanos, sírios e cubanos, mas não dos venezuelanos. Com a citação anterior, não há dúvidas de que a imigração para o Brasil foi motivada por dois motivos: pelas perspectivas do cenário econômico e do mercado de trabalho e pela propaganda, propagandização, do país pelo próprio governo Rousseff, com chancela do Itamaraty. Está comprovada a nossa hipótese.

Para finalizar esta seção, é meritório retomarmos as posições do chanceler Mauro Vieira, o último de Dilma Rousseff, em relação às questões migratórias, que, ainda, tiveram um tratamento destacado no primeiro semestre de 2015 e passaram para o segundo plano a partir do segundo semestre daquele ano, em virtude da necessidade de "defesa pela 
Campos Neutrais - Revista Latino-Americana de Relações Internacionais Vol. 2, $\mathrm{N}^{\mathrm{O}}$ 3, Setembro-Dezembro de 2020. Santa Vitória do Palmar - RS.

sobrevivência" do agonizante governo Rousseff, já no processo de impeachment.

Não podemos afirmar que há uma mudança de discurso de Figueiredo para Vieira, mas uma complementação e uma maior preocupação do governo brasileiro com o acolhimento de imigrantes, sobretudo, caribenhos e oeste-africanos, dada a perspectiva de agravamento do cenário econômico e político do Brasil.

Em sua última audiência como chanceler brasileiro na Comissão de Relações Exteriores e Defesa Nacional, em 03 de setembro de 2015, Vieira comentou o seguinte sobre o tratamento dispensado pelo governo brasileiro às migrações:

No caso do Brasil, que uma legislação muito específica, e o Senador Aloysio Nunes Ferreira tem um projeto que está sendo... O SR. PRESIDENTE (Aloysio Nunes Ferreira. Bloco Oposição/PSDB - SP) Já foi aprovado aqui no Senado em decisão terminativa na nossa Comissão, e agora está na Câmara. A mudança no Estatuto do Imigrante. O SR. MAURO LUIZ ICKER VIEIRA - Do Imigrante. E a nossa atuação atualmente é de acordo com a legislação em vigor. $O$ Brasil dá o status de refugiado aos que chegam e dá também vistos para a reunião familiar. $E$ temos feito um grande esforço justamente para atender essa grande demanda, que vem sobretudo do Haiti, país em que temos participação enorme. Primeiro, sempre apoiamos e sempre desenvolvemos programas de cooperação intensos, grandes, importantes, há muitos anos. Depois, a partir da criação da força das Nações Unidas para Estabilização, a Minustah (Missão das Nações Unidas para a Estabilização do Haiti), em que comandamos a força e temos o maior contingente, também com um envolvimento muito grande... (Soa a campainha.) O SR. MAURO LUIZ ICKER VIEIRA ...um envolvimento enorme. Fizemos doações humanitárias, de alimentos, doações financeiras para um número infindável de iniciativas, de projetos de cooperação, inclusive para a construção de obras de infraestrutura, justamente para criar condições de fixar os cidadãos haitianos no território haitiano e evitar esse deslocamento tão grande para o Brasil. A Embaixada do Brasil tem feito um grande esforço, e estamos concedendo cerca de 2 mil vistos por mês. Houve um enorme esforço, físico inclusive, porque a Embaixada tem evidentemente recursos limitados, mas tem feito um grande esforço, todos os funcionários - do embaixador a todos os funcionários - para concessão de vistos a um número muito mais alto. É um trabalho muito complexo. As pessoas, às vezes, não têm verdadeira noção do que envolve um visto - exame de documentos, verificação da legitimidade dos documentos e tudo. O SR. PRESIDENTE (Aloysio Nunes Ferreira. Bloco Oposição/PSDB - SP) Na Síria? O SR. MAURO LUIZ ICKER VIEIRA - Não, estou dizendo no Haiti, por enquanto. E formando inclusive longas filas na porta da embaixada. Temos feito um grande esforço para atender essa demanda, reduzir essa espera e reduzir as filas, dentro do que estabelece a lei. Na Síria, temos evidentemente também, e recebemos, mas até em um nível menor, imigrantes, o que não é nada de estranhar, porque já recebemos um contingente enorme desde o fim do império otomano, da época da Primeira Guerra Mundial. São cerca de quatro milhões de brasileiros de origem síria que têm contribuído ativamente, no Estado de São Paulo, 
sobretudo, uma colônia. Não se pode mais chamar de colônia porque são brasileiros já, totalmente, de segunda, terceira e quarta geração, que se integraram perfeitamente à sociedade brasileira e deram uma contribuição muito importante. 13:36 Eu acho que o Brasil, como país aberto e generoso que é, deve continuar a receber esses contingentes e sempre de acordo com a legislação. O SR. LINDBERGH FARIAS (Bloco Apoio Governo/PT - RJ) - Segundo os números que tenho aqui, o Brasil recebeu 1.700 sírios, refugiados, recentemente. É o maior número na América Latina. Acho que temos que continuar com essa política em um momento de gravidade da situação internacional, em especial daquela região síria. O SR. MAURO LUIZ ICKER VIEIRA - Eu não tenho dúvida de que é o gesto que podemos fazer em cooperação e em apoio à situação humanitária tão grande, já que não temos outros meios, porque somos pela solução pacífica e negociada, pela via diplomática das controvérsias, dos conflitos, e não temos uma participação, uma voz que seja definitiva em outros organismos. Não estamos, no momento, no Conselho de Segurança das Nações Unidas como membro não permanente, porque há um rodízio, evidentemente, e nesse momento não estamos, mas acho que essa atuação é fundamental. Acho que é o gesto que podemos fazer para essas populações desatendidas, muitas das quais têm parentes próximos do Brasil. Obrigado (BRASIL, 2015, grifos nossos).

A citação anterior deixa margem para a inferência de que a estratégia do governo à época, uma vez que as expectativas da $1^{\text {a }}$ COMIGRAR haviam sido frustradas com todo o ciclo de crises e com a interrupção da agenda governamental por causa do processo de impeachment, era constituída de dois pontos: 1) evitar que novos imigrantes chegassem ao Brasil, ou seja, a contenção por meio da cooperação e das missões humanitárias (algo que já discorremos no começo deste trabalho; e 2) usar o discurso humanitário e seu capital político para justificar perante a sociedade e a própria ONU as ações do governo brasileiro no acolhimento dos imigrantes.

A partir da leitura destes discursos e da sua incorporação na nossa hipótese e das questões dimensionais, depreendemos como a inserção estratégica do Brasil foi causadora das migrações de latino-americanos e africanos para o país e como esta mesma inserção, por meio da política externa migratória brasileira, foi utilizada para gerir a incipiente crise migratória que começaria em 2014 e se prolongaria pari passu com a crise doméstica brasileira até, no mínimo, 2018; já, na administração Michel Temer, com a imigração venezuelana.

Identificamos, também, os três eixos de inserção estratégica: o Programa Mais Médicos, primeira iniciativa governamental brasileira de imigração subsidiada desde a Segunda Guerra Mundial, os programas de cooperação e concessão de bolsas de estudo e pesquisa e, por fim, a propagandização do país pelas redes migratórias e internacionais do trabalho como uma alternativa aos destinos tradicionais. 
Campos Neutrais - Revista Latino-Americana de Relações Internacionais Vol. 2, $\mathrm{N}^{\mathrm{O}}$ 3, Setembro-Dezembro de 2020. Santa Vitória do Palmar - RS.

\section{Considerações Finais}

Segundo Cogo (2014), as redes migratórias do trabalho foram fundamentais para que se concretizasse a criação de um "Eldorado brasileiro" e a transformação de sonho em pesadelo após o tensionamento econômico e político experimentado no Brasil, em 2014 e nos anos subsequentes. Conforme a autora:

A vivência multiterritorial em redes migratórias da diáspora haitiana que contribui para impulsionar a própria migração pra o Brasil pode ser entendida na perspectiva do que Guarnizo (2004) define como um amplo espectro de relações sociais, culturais, políticas e econômicas transfronteiriças que conectam os migrantes a suas sociedades de origem. Essas relações situam em primeiro plano a capacidade de agência dos migrantes e envolvem um ativo e dinâmico campo de intercâmbio social que afeta os atores (indivíduos, grupos, instituições) localizados em diferentes contextos nacionais e locais. [...] A diáspora haitiana vai concorrer, assim, para a criação e manutenção de redes migratórias e o empreendimento de projetos de migração no interior dessas redes, além de operar para a reatualização de vínculos sociocomunicacionais entre imigrantes haitianos em diferentes espaços transnacionais, incluindo o Brasil e o Haiti. No caso da imigração haitiana, as redes migratórias evidenciam e ao mesmo tempo revitalizam o caráter familiar que vêm caracterizando o planejamento e implementação de projetos migratórios de haitianos para o Brasil. A interação em redes migratórias pode favorecer a autoproteção e solidariedade no percurso migratório assim como o confronto das condições de imigração encontradas no país em relação às demais nações que abrigam a diáspora haitiana no que se refere a ofertas de trabalho, níveis salariais, sistemas de envio de remessas ao Haiti, condições de moradia, etc. (COGO, 2014, p. 28).

Essas questões das redes como promotoras das migrações de perspectiva para o Brasil podem ser mais bem compreendidas a partir de dois instrumentos que apresentaremos a seguir: a via depoimental e a ilustração gráfica. Os próximos parágrafos trazem quatro depoimentos de imigrantes, cujos nomes foram preservados em virtude da ética científica e a pedido dos mesmos, dada a sua regularização migratória no Brasil não estar concluída no momento da redação deste trabalho:

Imigrante "A", cubano, médico, vivendo no Brasil desde 2014: "Eu descobri o programa dos Médicos por meio de uma parente que veio na primeira onda para cá [Brasil] e vi que era a possibilidade de sair da ilha e construir uma vida melhor. Graças a este programa do governo brasileiro eu pude sair de Cuba e enviar mais dinheiro para a minha família. Eu queria trazer os meus filhos para cá."

Imigrante "B", haitiano, engenheiro (industriário no Brasil), vivendo no Brasil desde 2013: "Viemos [ele e mais três amigos] para o Brasil porque era o melhor país na época, já que não conseguíamos o visto dos Estados Unidos e nem o refúgio no Canadá. Viemos pelo nosso dinheiro, sem 
esses coiotes que a imprensa diz. Tínhamos uma visão de que teríamos emprego aqui assim que chegássemos, mas levamos três meses até conseguir um trabalho. Nossos irmãos que vieram antes nos disseram que mudou muito."

Imigrante "C", senegalês, professor (vendedor ambulante no Brasil), vivendo no Brasil desde 2014: "A Copa do Mundo foi a nossa oportunidade para virmos ao Brasil, já que os vistos foram liberados e poderíamos entrar facilmente na Espanha depois de um tempo. Aqui é tudo muito diferente, só vim também porque os meus amigos que já estavam no Brasil me disseram que tinha emprego, saúde de graça e o povo era cordial. Nunca sofri preconceito até ano passado quando me disseram que eu teria que sair do país depois das eleições. Eu "tô" pensando em ir para a Argentina, mas não quero voltar para casa." Imigrante "D", guineense, advogado (estudante no Brasil), vivendo no Brasil desde 2016: "Eu vim porque sofria perseguição política em Bissau e porque o governo brasileiro ofereceu em 2015 algumas bolsas para nós africanos virmos estudar a pós-graduação aqui no Brasil. Hoje eu solicito refúgio, pois tenho amigos moçambicanos que já pediram, hoje têm família aqui. Não quero mais voltar. Quero trazer minhas filhas e minha esposa."1

Os depoimentos anteriores deixam evidente como o fator da rede migratória foi fundamental para que se concretizasse o plano de migrar do país de origem para o Brasil. Percebe-se, também, como as relações afetivas e familiares se mantêm presentes em todo o processo, sendo estas as forças motrizes que mais pesam, depois da perspectiva do país de destino, no ato decisório de migrar ou não.

A Figura 2 ilustra, por fim, as duas forças de pressão e de propagandização que levaram à migração em massa de africanos e latino-americanos para o Brasil durante o período dos governos Lula da Silva e Rousseff; essas forças de pressão serão denominadas de "matriz decisória de migração baseada em perspectivas":

\footnotetext{
${ }^{1}$ Esses depoimentos foram coletados pelo autor, por meio de entrevistas informais com os quatro imigrantes, entre fevereiro e outubro de 2018, nas cidades de Novo Hamburgo, Torres e Porto Alegre, todas localizadas no Rio Grande do Sul. A identidade dos depoentes e a íntegra das entrevistas serão mantidas sob sigilo para fins de preservação do status migratório dos entrevistados.
} 
Figura 2 - Matriz decisória de migração baseada em perspectivas

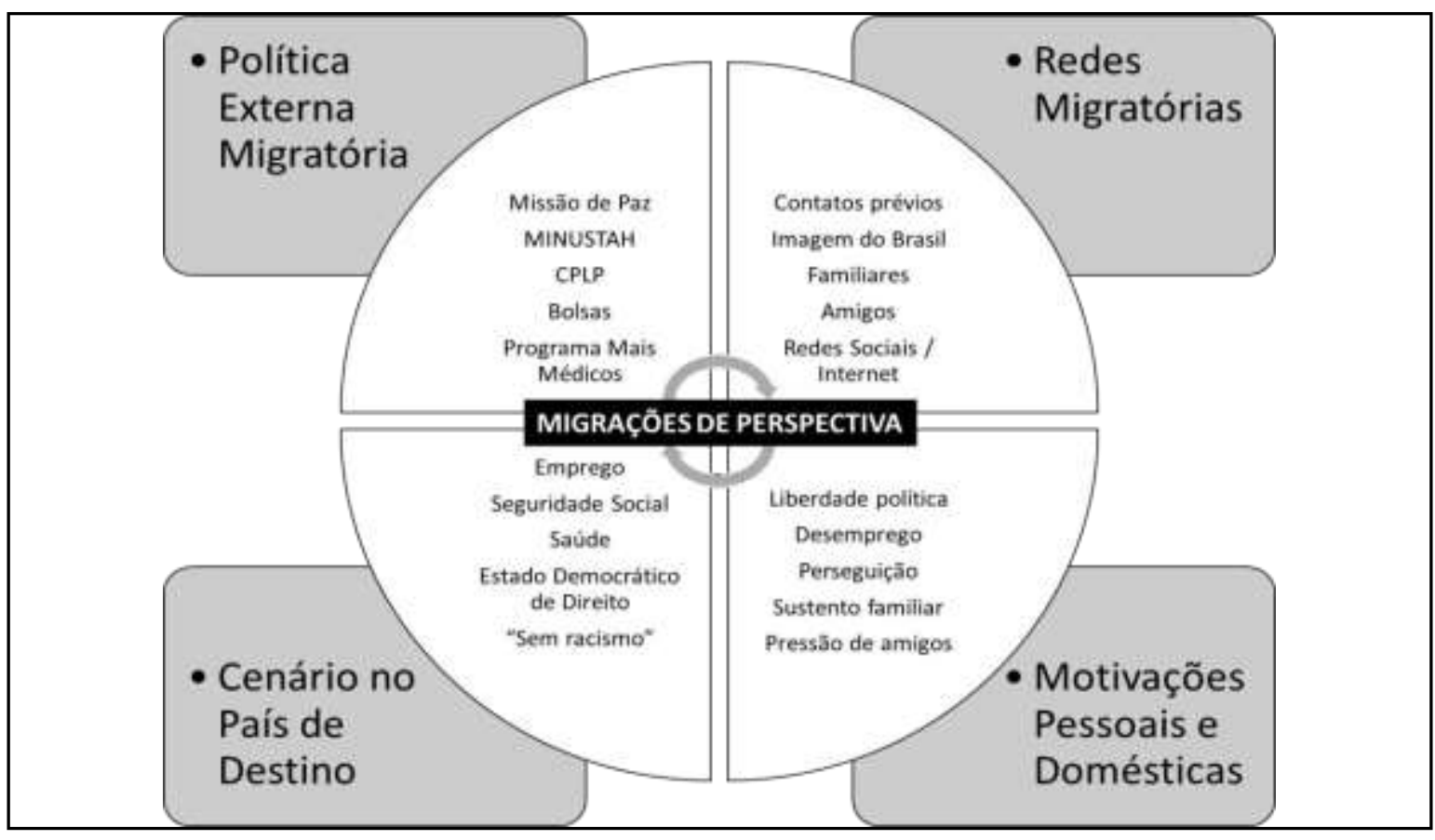

Fonte: Elaborada pelos autores.

A Figura 2 sintetiza toda a discussão que fizéramos até aqui em relação às motivações, por parte dos africanos e latino-americanos, para migrar ao Brasil e como elas se apresentam como uma resposta, uma consequência da política externa migratória brasileira de 2003 a 2016; ademais de se relacionarem tal como uma das engrenagens que conduziram e sustentaram toda a agenda da política externa migratória brasileira.

Essa matriz, conforme vimos, começa a se modificar e a perder vulto com a hiperdinamização migratória, um elemento externo, portanto, e o agravamento do cenário de crises no Brasil.

Isto posto, é possível inferir como os elementos extrapolítica externa migratória estão a condicionar o novo outlook migratório do Brasil, hiperdinamizando-o e criando novas bases para novas imigrações e - aí o elemento novo - emigrações de perspectiva, agora, de novos grupos, os de brasileiros - tema para discussão em pesquisas futuras. Espera-se, portanto, com este trabalho, ter possibilitado o debate e a compreensão maior acerca das agendas e das políticas externas migratórias dos governos Lula da Silva e Rousseff e como influenciaram o cenário migratório dos dois governos posteriores. 
Campos Neutrais - Revista Latino-Americana de Relações Internacionais Vol. 2, $\mathrm{N}^{\mathrm{O}}$ 3, Setembro-Dezembro de 2020. Santa Vitória do Palmar - RS.

\section{Referências}

BRASIL. Câmara dos Deputados. Comissão de Relações Exteriores e Defesa Nacional. Evento: Audiência Pública. Reunião no: 0512/14. Brasília, DF: Departamento de Taquigrafia, Revisão e Redação, 7 maio 2014. Disponível em: <https://goo.gl/2pFgNX>. Acesso em: 03 jul. 2019.

BRASIL. Senado Federal. Comissão de Relações Exteriores e Defesa Nacional. Notas taquigráficas: 03/09/2015 - 31 - Comissão de Relações Exteriores e Defesa Nacional. Brasília, DF, 3 set. 2015. Disponível em: <https://www25.senado.leg.br/web/atividade/notas-taquigraficas//notas/r/3727>. Acesso em: 03 jul. 2019.

COGO, Denise. Haitianos no Brasil: comunicação e interação em redes migratórias transnacionais. Chasqui - Revista Latinoamericana de Comunicación, Quito, n. 125, p. 23-32, mar. 2014. Disponível em: 〈http://revistachasqui.org/index.php/chasqui/article/view/39>. Acesso em: 03 jul. 2019.

DILMA demite ministro Patriota após episódio com senador boliviano. In: G1. Política. Brasília, 26 ago. 2013. Disponível em: <http://g1.globo.com/politica/noticia/2013/08/dilma-demiteministro-patriota-apos-episodio-com-senador-boliviano.html>. Acesso em: 03 jul. 2019.

DILMA foi alvo de espionagem dos EUA, diz TV. In: UOL NOTÍCIAS. Internacional. São Paulo, 02 set. 2013. Disponível em: <https://noticias.uol.com.br/internacional/ultimasnoticias/2013/09/02/dilma-foi-alvo-de-espionagem-dos-eua-diz-reportagem.htm>. Acesso em: 03 jul. 2019.

DISCURSO do Ministro Antonio de Aguiar Patriota por ocasião da cerimônia de transmissão do cargo de Ministro de Estado das Relações Exteriores. In: MINISTÉRIO DAS RELAÇÕES EXTERIORES. Discursos. Brasília, 02 jan. 2011. Disponível em: <http://www.itamaraty.gov.br/pt-BR/discursos-artigos-e-entrevistas-categoria/ministro-dasrelacoes-exteriores-discursos/4572-discurso-do-ministro-antonio-de-aguiar-patriota-na-cerimoniade-transmissao-do-cargo-de-ministro-de-estado-das-relacoes-exteriores>. Acesso em: 03jul. 2019.

FAMÍLIAS de refugiados afegãos deixam o Brasil. In: O Estado de São Paulo. Internacional. São Paulo, 20 maio 2003. Disponível em: <https://internacional.estadao.com.br/noticias/geral,familiasde-refugiados-afegaos-deixam-o-brasil,20030520p29112>. Acesso em: 03 jul. 2019.

FONSECA, Carmen. A política externa brasileira da democracia: O paradoxo da mudança na continuidade?. Relações Internacionais, Lisboa, n. 29, p. 33-43, mar. 2011. Disponível em:

$<$ http://www.scielo.mec.pt/scielo.php?script=sci_arttext\&pid=S1645-

91992011000100003\&lng=pt\&nrm=iso >. Acesso em: 03 jul. 2019.

GREEN, Nancy L. Expatriation, Expatriates, and Expats: The American Transformation of a Concept. The American Historical Review, Oxford, v. 114, n. 2, p. 307-328, abr. 2009. Disponível em: < https://www.jstor.org/stable/30223780>. Acesso em: 03 jul. 2019.

ISRAEL chama Brasil de 'anão diplomático' por convocar embaixador. In: G1. Mundo. São Paulo, 24 jul. 2014. Disponível em: <http://g1.globo.com/mundo/noticia/2014/07/israel-lamenta-decisaodo-brasil-de-convocar-embaixador-em-tel-aviv.html>. Acesso em: 03 jul. 2019.

MERCOSUL rejeita novas regras de imigração da UE. In: BBC Brasil. Repórter BBC. San Miguel de Tucumán, 01 jul. 2008. Disponível em: <https://www.bbc.com/portuguese/reporterbbc/story/2008/07/080630_mercosulcupulaimigracao_ mc_ac.shtml>. Acesso em: 03 jul. 2019.

MINBAEVA, Dana B.; MICHAILOVA, Snejina. Knowledge transfer and expatriation in multinational corporations: The role of disseminative capacity. Employee Relations, Bingley, v. 26, n. 6, p. 663-679, 2004. Disponível em: 〈https://doi.org/10.1108/01425450410562236>. Acesso em: 03 jul. 2019.

POLÍTICA de imigração brasileira precisa ser revista, diz Amorim. In: O GLOBO. Brasil. Rio de Janeiro, 13 jan. 2012. Disponível em: <https://oglobo.globo.com/brasil/politica-de-imigracao- 
Campos Neutrais - Revista Latino-Americana de Relações Internacionais Vol. 2, $\mathrm{N}^{\mathrm{O}}$ 3, Setembro-Dezembro de 2020. Santa Vitória do Palmar - RS.

brasileira-precisa-ser-revista-diz-amorim-3660191>. Acesso em: 03 jul. 2019.

REIS, Rossana Rocha. A Política do Brasil para as Migrações Internacionais. Contexto

Internacional, Rio de Janeiro, v. 33, n. 1, p. 47-69, jan./jun. 2011. Disponível em:

$<\mathrm{http}$ ://contextointernacional.iri.puc-rio.br/cgi/cgilua.exe/sys/start.htm?infoid=545\&sid=75>.

Acesso em: 03 jul. 2019.

SASSEN, Saskia.Una sociología de la globalización. Buenos Aires: Katz Editores, 2007.

SEYFERTH, Giralda. Imigrantes, estrangeiros: a trajetória de uma categoria incomoda no campo político. In: 26 ${ }^{\mathbf{a}}$ Reunião Brasileira de Antropologia, 2008, Porto Seguro. Anais da $\mathbf{2 6}^{\mathbf{a}}$ Reunião Brasileira de Antropologia. Brasília: Associação Brasileira de Antropologia, 2008. Disponível em:

<http://www.abant.org.br/conteudo/ANAIS/CD_Virtual_26_RBA/mesas_redondas/trabalhos/MR $\% 2012$ /giralda\%20seyferth.pdf $>$. Acesso em: 03 jul. 2019.

SANTOS, Milton. Fim de século e globalização. São Paulo: Hucitec, 1993.

SOUZA, Jessé. A Elite do Atraso. São Paulo: LeYa, 2017.

UEBEL, Roberto Rodolfo Georg. Migrações internacionais e agência estatal: o estado da arte no Brasil. Beau Bassin: Novas Edições Acadêmicas, 2017.

UEBEL, Roberto Rodolfo Georg. Política externa migratória brasileira: das migrações de perspectiva à hiperdinamização das migrações durante os governos Lula da Silva e Dilma Rousseff. Tese de Doutorado em Estudos Estratégicos Internacionais, Universidade Federal do Rio Grande do Sul, 2018. Disponível em: 〈http://hdl.handle.net/10183/188410>. Acesso em: 03 jul. 2019.

VIZENTINI, Paulo Fagundes. De FHC a Lula: Uma década de política externa (1995-2005). Civitas, Porto Alegre, v. 5, n. 2, p. 381-397, jul./dez. 2005. Disponível em: $<$ https://www.lume.ufrgs.br/bitstream/handle/10183/144014/000527985.pdf?sequence=1>. Acesso em: 03 jul. 2019.

\author{
EDITORA E GRÁFICA DA FURG \\ CAMPUS CARREIROS \\ CEP 96203900 \\ editora@furg.br
}

